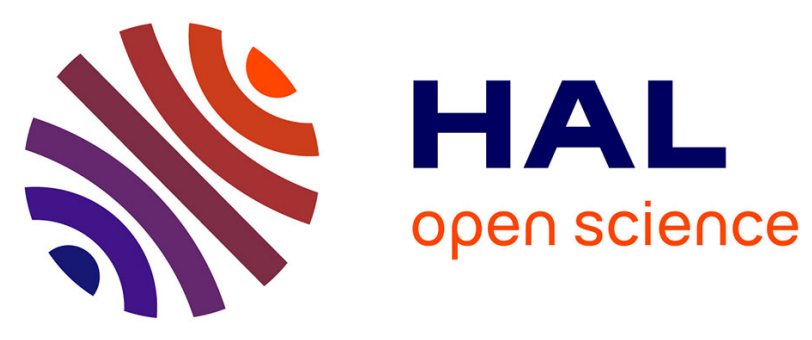

\title{
Electrically Conductive Thin Films Based on Nanofibrillated Cellulose: Interactions with Water and Applications in Humidity Sensing
}

Katariina Solin, Maryam Borghei, Ozlem Sel, Hannes Orelma, Leena-Sisko Johansson, Hubert Perrot, Orlando Rojas

\section{To cite this version:}

Katariina Solin, Maryam Borghei, Ozlem Sel, Hannes Orelma, Leena-Sisko Johansson, et al.. Electrically Conductive Thin Films Based on Nanofibrillated Cellulose: Interactions with Water and Applications in Humidity Sensing. ACS Applied Materials \& Interfaces, 2020, 12, pp.36437-36448. 10.1021/acsami.0c09997 . hal-02912030

\section{HAL Id: hal-02912030 \\ https://hal.sorbonne-universite.fr/hal-02912030}

Submitted on 4 Jan 2021

HAL is a multi-disciplinary open access archive for the deposit and dissemination of scientific research documents, whether they are published or not. The documents may come from teaching and research institutions in France or abroad, or from public or private research centers.
L'archive ouverte pluridisciplinaire HAL, est destinée au dépôt et à la diffusion de documents scientifiques de niveau recherche, publiés ou non, émanant des établissements d'enseignement et de recherche français ou étrangers, des laboratoires publics ou privés. 


\section{Electrically Conductive Thin Films Based on}

\section{Nanofibrillated Cellulose: Interactions with Water}

\section{and Its Application as Humidity Sensor}

Katariina Solin ${ }^{\dagger}$, Maryam Borghei ${ }^{\dagger}$, Ozlem Sel $^{* \ltimes}$, Hannes Orelma $^{*}$, Leena-Sisko Johansson ${ }^{\dagger}$, Hubert Perrot ${ }^{\alpha}$ and Orlando J. Rojas ${ }^{* * \theta}$

'Department of Bioproducts and Biosystems, School of Chemical Engineering, Aalto University, Vuorimiehentie 1, FI-00076, Espoo, Finland

${ }^{a}$ Sorbonne Université, CNRS, Laboratoire Interfaces et Systèmes Electrochimiques, LISE, UMR 8535, 75005 Paris, France

tVTT Technical Research Centre of Finland, Tietotie 4, FIN-02044 VTT, Finland

${ }^{\theta}$ The Bioproducts Institute, Departments of Chemical and Biological Engineering, Chemistry and Wood Science, University of British Columbia, 2360 East Mall, Vancouver, BC, V6T 1Z4 Canada

Keywords: Humidity sensing; conductive ink; nanocellulose; carbon nanotubes; quartz crystal microbalance with impedance measurement (QCM-I); viscoelastic properties; water interactions. 


\section{ABSTRACT}

This work accentuates the interactions of water vapor with electrically conductive thin films based on nanofibrillated cellulose. Conductive inks, made with TEMPO-oxidized cellulose nanofibrils (TOCNF) and oxidized carbon nanotubes (CNT), were cast as humidity responsive films on substrates, and sensing properties were evaluated via electroacoustic admittance or electrical resistivity. Quartz crystal microbalance with impedance monitoring (QCM-I) was used to monitor gravimetrical, viscoelastic and mechanical parameters through the analyses of electroacoustic admittance. Water-uptake and swelling phenomena were investigated in relative humidity $(\% \mathrm{RH})$ range of $30-60 \%$ and temperature ranges of $25-50{ }^{\circ} \mathrm{C}$. The system displayed fast and sensitive response to changes in humidity, and mass gain up to $20 \%$ was measured within the tested $\% \mathrm{RH}$ and $\mathrm{T}$. The results indicate that the presence of CNT endowed the fibril network with higher water accessibility. Besides, the TOCNF-based sensing element became viscoelastic upon water uptake, as quantified by the Martin-Granstaff model. The CNT in sensors enabled humidity detection via electrical resistance measurement. By increasing the \% RH of air from 20 to $60 \%$, the sensor resistance increased by ca. $15 \%$, a similar level for both glass and paper substrates. Substrate adhesion, response to cyclic \% RH, bending and durability studies were performed to determine the operational window. The composite inks and derived sensor films offer a great potential to monitor humidity changes in smart packaging, most relevant in tracking conditions of food and pharmaceutical products. 


\section{INTRODUCTION}

Water interactions influence greatly the properties of cellulosic materials and the performance of cellulose-based products. Therefore, understanding the water-cellulose interactions is crucial in for example packaging, cosmetic, and pharmaceutical applications. In addition, there is a growing interest for novel applications where these interactions can be advantageously used, for instance in membranes for water purification or humidity sensing ${ }^{1-4}$.

Cellulose has amphiphilic properties due to its anisotropic chemical structure ${ }^{5}$. While, cellulose and its nanosized forms, such as cellulose nanofibrils, are hygroscopic, they do not dissolve in water ${ }^{5,6}$. The high affinity to water is the result of the large density of hydroxyl groups on the surface of cellulosic materials, which can be further enhanced via oxidation. For example, by 2,2,6,6-tetramethylpiperidine-1-oxyl radical (TEMPO)-mediated oxidation, in which one or more hydroxyl groups at the cellulose C6-position can be replaced with carboxyl groups ${ }^{7}$. At high humidity and compared to the hydroxyls, the carboxyl groups dissociate and show higher affinity to water ${ }^{2}$. For instance, Piringer et al. ${ }^{9}$ reported polymer molar water content per structural groups of 2.1 for dissociated carboxyl groups versus 0.5 for hydroxyl groups at $50 \% \mathrm{RH}$ and $25{ }^{\circ} \mathrm{C}$.

There are several models explaining the sorption behavior of water vapor and gases onto various cellulosic materials ${ }^{10-14}$. For example, combinations of the Langmuir adsorption, Henry's Law and Flory-Huggins solution theories have been used for the development of these models ${ }^{15-18}$. Twostep sorption processes such as Hailwood-Horrobin sorption and parallel exponential kinetics (PEK) models have been utilized ${ }^{10,12}$. Besides, three-component models such as Langmuir/FloryHuggins/clustering model have also been reported ${ }^{15}$. 
To investigate experimentally cellulose water uptake, Dynamic Vapor Sorption (DVS) is a wellestablished method ${ }^{10,13,19,20}$. Lundahl et al. ${ }^{19}$ used DVS to study water uptake by cellulose filaments in humid conditions, revealing stronger water affinity of TOCNF filaments compared to those spun from CNF. In addition, Belbekhouche et al. ${ }^{10}$ investigated water vapor uptake by nanocellulose films using DVS and observed that diffusion of water was a two-step process controlled by the surface rather than the core of the films ${ }^{10}$. Quartz crystal microbalance (QCM) have also been used. For example, Hakalahti et al. ${ }^{15}$ studied water vapor uptake and swelling of TOCNF films by using a QCM with humidity control by using saturated salt solutions. Besides, Tammelin et al. ${ }^{21}$ has also employed QCM to study water vapor uptake, swelling and water-induced morphological changes of regenerated cellulose films. These recent reports described a three-step water sorption where initially water molecules bind to surface hydroxyl groups, then water forms monolayer and clusters, and finally, water accumulates abundantly inside the films ${ }^{15,21}$. Moreover, QCM has also been employed as a humidity sensing device by integrating it with non-cellulosic fibrous networks, for example, by using polyethyleneimine-grafted polyacrylonitrile nanofibrous mats as active layer $^{22}$.

Paper electronics have gained lots of interest recently and are considered as potential costeffective, eco-friendly alternatives in various applications, including batteries, photovoltaic substrates and various types of sensors ${ }^{23-25}$. Paper and cellulosic materials are especially interesting for humidity sensing since in this application the hygroscopic behavior of cellulose can be advantageously exploited ${ }^{3,26-29}$. In addition, cellulose offers the possibility to replace some of the non-green components used in humidity sensors, enabling reduction in the negative environmental impact of these devices upon production and disposal. Usually, cellulosic materials have been used in such sensors as a passive support, on which the electrically conductive elements 
are deposited. For example, carbon- or silver-based conductive elements have been deposited on paper to produce humidity sensors ${ }^{26,28-30}$. Han et al. ${ }^{28}$ entangled a single-walled carbon nanotube network on paper and demonstrated its ability to work as a humidity sensor. Feng et al. ${ }^{29}$ obtained humidity sensors by inkjet printing silver nanoparticles on different paper substrates. On the other hand, humidity sensors have been produced by forming conductive cellulose composite films or by depositing cellulose-based conductive inks on different substrates ${ }^{3,4,31}$. Zhu et al. ${ }^{4}$ produced flexible humidity sensors from composite films of nanocellulose and carbon nanotubes (CNTs) by vacuum filtration. Whereas, Barras et al. ${ }^{3}$ used carboxymethyl cellulose and carbon fibers to produce screen-printable ink and tested its suitability for paper-based humidity sensing.

Despite the advances reached by the cited studies on cellulose-water interactions and sensing with conductive systems based on cellulose, water interactions with conductive cellulose composites is still an area that has not been explored thus far. This is quite relevant in any future development that attempts to deploy such features in this type of humidity sensing. Hence, here we investigated the changes in gravimetric and viscoelastic parameters of conductive CNTnanocellulose films by using QCM with impedance monitoring (QCM-I) under different relative humidity (\% RH). Thus, with these measurements, we are able to observe water interactions with the humidity responsive composite films and give further insight into the sensing behavior of the derived sensors.

In this work, conductive inks were prepared by dispersing CNT in an aqueous suspension of TEMPO-oxidized cellulose nanofibrils (TOCNF) and used to cast conductive films with humidity responsiveness. A humidity chamber equipped with a QCM-I probe was used to study the interactions between water and TOCNF films as well as the respective conductive composite films (TOCNF-CNT). The humidity chamber allowed precise \% RH and temperature control during the 
QCM-I measurements. This coupling enabled measurements of the water uptake and the induced gravimetric and mechanical changes of TOCNF and TOCNF-CNT films at 30-60\% RH and 25$50{ }^{\circ} \mathrm{C}$. The experimental QCM-I data were analyzed by two different models, Sauerbrey ${ }^{32}$ and the Martin-Granstaff ${ }^{33}$, to account for the gravimetric and viscoelastic properties during water vapor exposure. The humidity responsive conductive material was employed as humidity sensors on glass and paper substrates and their performance was characterized. The electrical properties of the composite films were determined with resistance measurements at $20-60 \% \mathrm{RH}$ and $23{ }^{\circ} \mathrm{C}$, and the effect of film thickness, substrate material and CNT content on humidity sensing was evaluated.

\section{EXPERIMENTAL SECTION}

Materials. TOCNF were produced from bleached Kraft birch pulp fibers according to the procedure reported elsewhere ${ }^{34}$. Multiwalled carbon nanotubes with average $15 \mathrm{~nm}$ diameter and $3 \mu \mathrm{m}$ length were obtained from Showa Denko, Japan. Sulfuric acid and nitric acid were purchased from Merck and ethanol (99.5\%) from Altia. PowerCoat ${ }^{\circledR}$ HD papers were kindly provided by Guarro Casas. They consist of paper coated with a polymer layer, that makes them suitable as substrates for advanced printed electronics such as capacitors, sensors and highly complex circuitry. Moreover, they can be used in printing operations such as inkjet, flexo, gravure and screen printing. ${ }^{35}$ Polyethyleneimine (PEI) 50\% aqueous solution and cetrimonium bromide (CTAB) were purchased from Sigma-Aldrich. Silver conductive paint was acquired from Electrolube. The water used in the experiments was purified using a Millipore Synergy UV unit (Milli-Q). 
Functionalization of the CNTs. The carbon nanotubes (CNTs) were modified by introducing carboxylic groups onto their surfaces, which improved aqueous dispersion with nanocellulose ${ }^{36}$. Briefly, CNTs were added to a mixture comprising $100 \mathrm{ml}$ nitric acid $(2 \mathrm{M})$ and $100 \mathrm{ml}$ sulfuric acid $(1 \mathrm{M})$ in a round-bottom flask. Oxidation was performed at $120^{\circ} \mathrm{C}$ for $4 \mathrm{~h}$, and a reflux system was used to condensate the evaporated acids. After oxidation, the functionalized CNTs were filtered and washed with water and ethanol. Finally, they were placed in an oven at $105{ }^{\circ} \mathrm{C}$ overnight. For simplicity, the functionalized multiwalled carbon nanotubes are herein referred to as CNTs.

X-ray photoelectron spectroscopy (XPS). In order to confirm the oxidation of the CNTs, their surface chemical compositions, before and after functionalization, were analyzed with an AXIS Ultra electron spectrometer (Kratos Analytical, Manchester, U.K.) utilizing a monochromatic Al Ka X-ray source at $100 \mathrm{~W}$ and a neutralizer. Samples were attached on the sample bar with UHV compatible carbon tape, together with the in-situ reference sample of pure cellulose ${ }^{37}$, and preevacuated overnight before the measurements. Wide energy range spectra were recorded for surface elemental analysis using $80 \mathrm{eV} \mathrm{CAE}$ and $1 \mathrm{eV}$ step, while high-resolution regions of carbon $\mathrm{C}$ 1s and oxygen $\mathrm{O} 1 \mathrm{~s}$ regions were also recorded for a more detailed chemical information, using $20 \mathrm{eV}$ CAE and $0.1 \mathrm{eV}$ step. Both samples were analyzed from three locations (analysis area less than $1 \mathrm{~mm}^{2}$ ). Data were processed with CasaXPS software. According to the reference data, vacuum conditions remained good and no contamination was detected.

Preparation of conductive inks. Several conductive inks were prepared by dispersing CNT and TOCNF, at given ratios. First, CNTs were dispersed in water by using a tip sonicator (Branson sonifier S-450 D) for $10 \mathrm{~min}$. Then, water-dispersed CNTs were mixed with the aqueous TOCNF 
suspension $(1.44 \mathrm{wt} \%)$ so that the final concentration of the inks was $0.5 \mathrm{wt} \%$ TOCNF with 0.05 , $0.075,0.1$ or $0.125 \mathrm{wt} \%$ CNTs. Bath sonication and shaking were used several times and, finally, a homogenizer (IKA T18 basic Ultra-Turrax) was used to improve the homogeneity of the gels. Thereafter, the conductive inks based on TOCNF and CNT are referred to as TOCNF-CNT inks.

Rheological properties of the conductive inks. The shear viscosity of the conductive TOCNFCNT inks was measured with a dynamic rotational rheometer (MCR 302, Anton Paar) and the results were compared to those of a $0.5 \mathrm{wt} \%$ TOCNF suspension. Parallel plates (PP25) were used with a gap fixed at $1 \mathrm{~mm}$. The changes in viscosity were measured by decreasing shear rate from $100 \mathrm{~s}^{-1}$ to $0.01 \mathrm{~s}^{-1}$. All samples were measured twice, and the measurements were performed at 23 ${ }^{\circ} \mathrm{C}$.

Thin film preparation on quartz resonators. Thin films were prepared for QCM-I measurements (see Table 1). Conductive films (TOCNF-CNT films) were prepared with the TOCNF-CNT ink $(0.05 \mathrm{wt} \% \mathrm{CNTs})$ by deposition on a gold electrode $\left(0.2 \mathrm{~cm}^{2}\right)$ of the QCM resonators $(9 \mathrm{MHz}$, AT-cut, diameter of $14 \mathrm{~mm}$ and average thickness of $180 \mu \mathrm{m}$, AWS Sensors, Spain). First, $5 \mu 1$ of $0.3 \mathrm{wt} \%$ PEI was drop-cast on top of QCM sensors, as an anchoring layer. Then, $5 \mu$ l of conductive ink ( $0.5 \mathrm{wt} \%$ dry matter content $)$ was drop-cast on top of the PEI-modified gold electrode and let to dry. To investigate the effect of loading, samples with lower loadings were prepared by depositing $5 \mu 1$ of diluted conductive ink ( $0.3 \mathrm{wt} \%$ dry solids) on top of PEIcoated sensors. Furthermore, to observe the effect of CNT, pristine TOCNF films were prepared as a reference, by drop-casting $5 \mu 1$ of pure $0.3 \mathrm{wt} \%$ and $0.5 \mathrm{wt} \%$ TOCNF suspensions on PEIcoated sensors.

The deposited masses, $\Delta m$, of the different samples were estimated by measuring the frequency changes, $\Delta f$, of the bare and loaded QCM resonators in air using the Sauerbrey equation (Eq. 1$)^{32}$ : 


$$
\Delta f_{m}=-k_{s} \Delta m=-\left(\frac{2 f_{0}^{2}}{-S n \sqrt{\rho_{q} \mu_{q}}}\right) \Delta m
$$

where $\Delta f_{m}$ is the frequency change of the microbalance, $k_{S}$ is the theoretical sensitivity coefficient (here, an experimental coefficient was used with a value of $16.8 \times 10^{7} \mathrm{~Hz} \mathrm{~g}^{-1} \mathrm{~cm}^{2}$ for a $9 \mathrm{MHz}$ crystal $)^{38}, \Delta m$ is the mass change on the microbalance active surface, $f_{0}$ is the fundamental resonant frequency of the quartz, $S$ is the active surface on the quartz corresponding to the metal electrode deposited on it, $n$ is the overtone number, $\rho_{q}$ is the quartz density $\left(2.648 \mathrm{~g} \mathrm{~cm}^{-3}\right)$, and $\mu_{q}$ is the shear modulus of a shear AT quartz crystal $\left(2.947 \times 10^{11} \mathrm{~N} \mathrm{~m}^{-2}\right)^{32,38}$. The Sauerbrey equation is only valid for thin rigid layers or very thin layers considered as acoustically thin enough. In air, it is possible to consider that our prepared films are sufficiently rigid as they are dry. Therefore, the loading value can be estimated by measuring the frequency difference between the bare and the corresponding loaded quartz resonator. In our case, four loadings were prepared (Table 1), and dry mass of $45 \mu \mathrm{g}$ and $82 \mu \mathrm{g}$ were obtained for TOCNF films, while values of $51 \mu \mathrm{g}$ and $96 \mu \mathrm{g}$ were obtained for TOCNF-CNT films. These samples are referred to as TOCNF_45, TOCNF_82, TOCNF-CNT_51 and TOCNF-CNT_96.

Water vapor uptake measurements by QCM-I. TOCNF and TOCNF-CNT films with the aforementioned loadings were analyzed via QCM-I at different \% RH levels and temperatures. Electroacoustic admittance measurements were performed using a network analyzer (Agilent $4294 \mathrm{~A})^{39,40}$, where the resonator is located inside a climatic chamber (CLIMACELL, Fisher Bioblock Scientific). The measurements were performed at $30-60 \% \mathrm{RH}$ and 25,35 and $50{ }^{\circ} \mathrm{C}$. The resulting experimental resonator electroacoustic admittance, $Y_{\exp }(\omega)$, were measured around at 9 $\mathrm{MHz}$ fundamental resonant frequency. Prior to the measurements, the films deposited on the quartz resonators were placed in the climatic chamber and stabilized at $30 \% \mathrm{RH}$ and $25^{\circ} \mathrm{C}$, until a stable 
baseline was observed. A custom-made software allowed access to the quartz resonant frequencies, $f$, during cycles of increasing/decreasing $\% \mathrm{RH}$ levels in the chamber at constant intervals. $\Delta f$ was used to estimate the mass changes, $\Delta m$, of the resonator, which were attributed to the adsorbed/desorbed water in the films. Direct correlation of $\Delta f$ to $\Delta m$ can be done with the Sauerbrey equation (Eq. 1), but only if the gravimetric regime is kept. As already mentioned, this equation is only suitable for thin rigid films.

Viscoelastic property changes as a function of \% RH. Viscoelastic films with higher thickness can dissipate a significant amount of energy, in which case the validity of the gravimetric regime is questionable ${ }^{41-43}$. The QCM-I method is based on admittance analysis of the quartz crystal resonator and the extraction of a classical equivalent circuit, which includes a motional branch, $R$, $L$, and $C$ in series with a capacitance, $C_{p}$, in parallel. Thus, the series resonant frequency, $f$, and the dissipation factor, $D$, can be determined. More precisely, $D$ is correlated to the bandwidth of the resonant conductance curve (Figure 1) and is also the inverse of the quality factor $(Q)$. As a first indication of the viscoelastic property changes, the dissipation factor, $D$, in response to $\% \mathrm{RH}$ level changes was evaluated using the following equation (Eq. 2):

$$
D=\frac{R}{2 \pi f L}
$$

where $R$ is the motional resistance, $f$ is the series resonant frequency and $L$ is the inductance of the quartz resonators ${ }^{44}$.

In an in-depth analysis, the viscoelastic film property changes were determined by fitting the experimental electroacoustic admittance, $Y_{t h}^{V}(\omega)$, based on a Martin-Granstaff viscoelastic mode $^{33}$. This analysis is relevant to estimate the contribution of viscoelastic changes on the $\Delta f$, and thus, to correctly correlate the latter to the true adsorbed/desorbed water mass ${ }^{33,39}$. The 
theoretical electrical admittance, $Y_{t h}^{V}(\omega)$, of the loaded QCM sensor was determined using equation 3 (Eq. 3):

$$
Y_{t h}^{V}(\omega)=\frac{1}{Z_{t h}^{V}(\omega)}=G+i S=i \omega C_{p}+\frac{1}{Z_{m}^{V} t h(\omega)}
$$

where $G$ is conductance, $S$ is susceptance, $\omega=2 \pi f, C_{p}$ is parallel capacitance and $Z_{m t h}^{V}(\omega)$ is the theoretical motional impedance of the loaded QCM sensor calculated with the viscoelastic model $^{33,39}$, as defined here by (Eq. 4):

$$
Z_{m}^{V}(\omega)=\frac{h_{q}^{2}}{4 e_{q}^{2} A} * Z_{f} * \frac{Z_{s}+Z_{f}\left(\tanh \left(\theta_{f} h_{f}\right)\right)}{Z_{f}+Z_{s}\left(\tanh \left(\theta_{f} h_{f}\right)\right)}
$$

where $h_{\mathrm{q}}$ is the quartz thickness, $e_{\mathrm{q}}$ is the quartz piezoelectric constant, $A$ is the active mass area, $Z_{f}$ is the acoustic impedance of the film, $Z_{s}$ is the acoustic impedance of the surrounding medium, $\theta_{f}$ is the complex propagation constant of the film and $h_{f}$ is the thickness. Moreover, $Z_{s}$ and $\theta_{f}$ can be described as (Eq. 5 and 6):

$$
\begin{aligned}
& Z_{f}=\sqrt{\rho_{f} G_{f}} \\
& \theta_{f}=\sqrt{\frac{\rho_{f}}{G_{f}}}
\end{aligned}
$$

where $\rho_{f}$ is the film density and $G_{f}$ is the shear modulus of the film, which can be written as a complex number with a real and imaginary part, $G_{f}=G^{\prime}+j G^{\prime \prime}$ or $G_{f}=\mu_{f}+j \eta_{f}$. It is noted that $j^{2}=-$ $1, G^{\prime}$ or $\mu_{f}$ are storage modulus and $G$ ”, or $\eta_{f}$ is the film viscosity.

A fitting example is given for two films, TOCNF_82 and TOCNF-CNT_96 (tested at $25^{\circ} \mathrm{C}$ and $30 \% \mathrm{RH}$ ), as can be seen in Figure 1. It allows key viscoelastic film parameters, film storage modulus, $\mu_{f}$, and the film viscosity, $\eta_{f}$, to be estimated. 

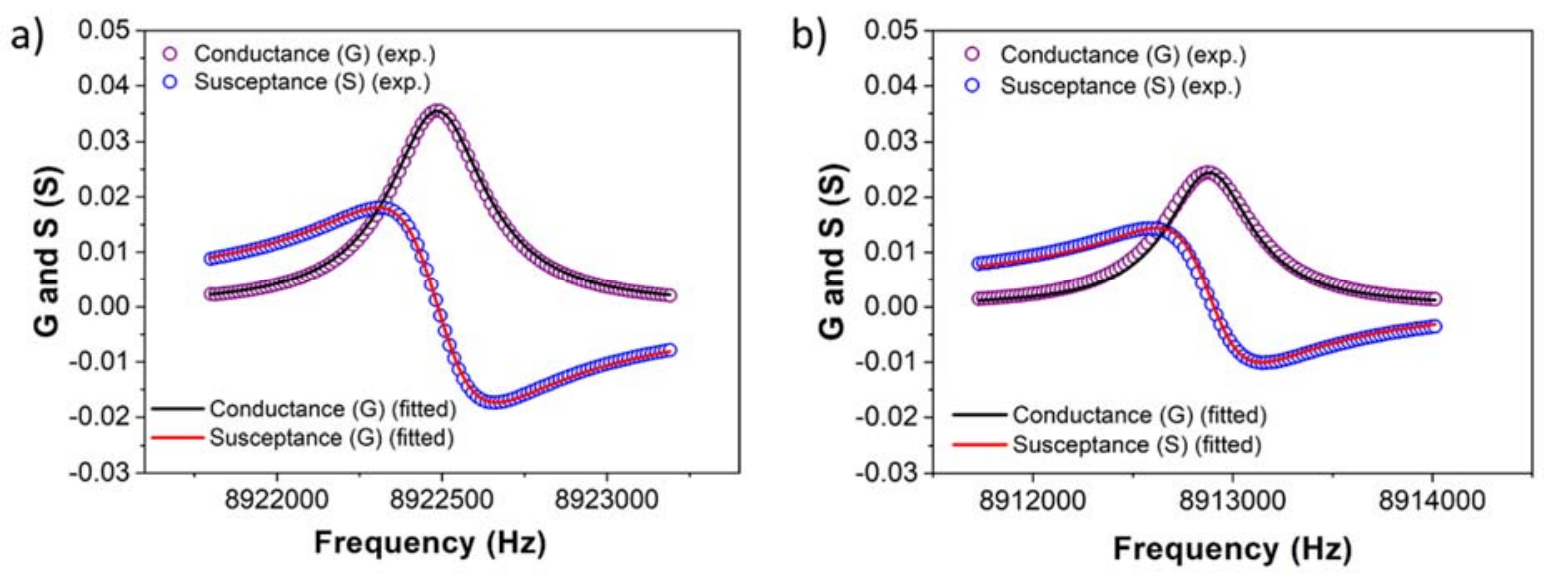

Figure 1. Experimental electroacoustic admittance, $Y_{\exp }(\omega)$, and fitted electroacoustic admittance, $Y_{\text {th }}^{V}(\omega)$, curves at $25^{\circ} \mathrm{C}$ and 30\% RH: a) TOCNF_82 and b) TOCNF-CNT_96 thin films deposited on the gold electrode of the quartz resonators.

Preparation of humidity sensors and electrical characterization. The TOCNF-CNT inks containing different amounts of CNTs $(0.05,0.075,0.1$ or $0.125 \mathrm{wt} \%)$ were used to prepare $1 \mathrm{~cm}$ x $5.5 \mathrm{~cm}$ patterns of different thicknesses on glass substrates. The thickness variations were obtained by rod coating $0.2,0.5$ or $1 \mathrm{ml}$ of each ink on tape-lined areas. The patterns were dried on a $75{ }^{\circ} \mathrm{C}$ hot plate (TOCNF:CNT ratios of the dried films can be seen in Table 1). Then, the tapes were removed, and copper contacts as well as silver conductive paint were applied at both ends. The sheet resistance of the samples (three replicates per sample) was measured under room conditions with a four-point multimeter. In addition, a two-point multimeter was used for resistance measurements under ambient conditions. To study the effect of the film dimension on resistance, the two-probe measurements were performed with $1.5 \mathrm{~cm}$ and $5.5 \mathrm{~cm}$ multimeter probe separation. Finally, humidity sensors were prepared on glass and paper (Powercoat ${ }^{\circledR}$ HD) substrates by spreading $0.3 \mathrm{ml}$ of each conductive ink on an area of $1.5 \mathrm{~cm} \times 1.5 \mathrm{~cm}$ with a similar 
method as described above. The performance of the humidity sensors was tested by measuring the resistance of the sensors (three replicates per sample) in a humidity chamber at $23{ }^{\circ} \mathrm{C}$ and $20-60 \%$ RH.

Scanning Electron Microscopy (SEM). SEM images of the thin films and humidity sensors were acquired with a field emission gun SEM (FEG-SEM) microscope (Zeiss Sigma VP) at 1.5 $\mathrm{kV}$. Unmodified Powercoat ${ }^{\circledR}$ HD paper, the substrate used for the humidity sensors, was also imaged on both sides. Prior to imaging, all samples were sputtered with an Au-Pd alloy using a glow discharge apparatus (Emitech K100X) at $30 \mathrm{~mA}$ for $1.5 \mathrm{~min}$.

Adhesion tests to substrate and surface treatments. Wet and dry adhesion tests were performed to verify the adherence of the conductive ink to the substrate. Wet adhesion was studied by observing the spreading of the ink while being applied on the substrate. Dry adhesion was evaluated using the tape method on dried TOCNF-CNT films on the Powercoat ${ }^{\circledR}$ HD substrate ${ }^{45,46}$. First, a piece of $\operatorname{Scotch}^{\mathrm{TM}}$ tape was applied over the dried patterns. Then, the tape was pulled at $90^{\circ}$ angle, and the adhesion to the substrate was evaluated after each tape pulling.

The above-mentioned adhesion tests were performed on three different surfaces including (i) unmodified, (ii) surfactant-treated and (iii) plasma-modified paper substrates. The surfactant treatment was done by spreading $0.2 \%$ CTAB solution on top of the substrate, and the plasma treatment was done in an ozone cleaner (BioForce Nanosciences UV-TC.110 UV Ozone Cleaner) for $120 \mathrm{~min}$.

Bending and resistance tests. The patterns of the conductive inks on paper substrates were exposed to tensile and compression bending (see schematic illustration in Figure S1) ${ }^{3,45}$. The bending was done for 20 times over two different bending radii $(0.55 \mathrm{~cm}$ and $1.45 \mathrm{~cm})$, and the 
resistance of the films was measured at room conditions with a two-point multimeter after relaxation between each bend.

\section{RESULTS AND DISCUSSION}

Ink formulation and characterization. The aqueous dispersion of CNT with TOCNF result in homogeneous, black-colored gels (see inset of Figure S2). The good homogeneity of the ink was enabled by CNT oxidation (i.e. functionalization with carboxylic groups) resulting in better hydrophilicity and dispersion in the TOCNF hydrogel. The XPS data (Figure S3) confirm successful oxidation, as shown by the increased $\mathrm{O} 1 \mathrm{~s}$ peak intensity after the oxidation.

The effect of CNT on the rheological behavior of the prepared inks was investigated (Figure S2). The apparent viscosity profiles of the inks, with varying CNT content, show similar shear thinning behavior, typical of nanocellulose in aqueous suspension ${ }^{47}$. CNT loading results in an increased viscosity at shear rates $<1 \mathrm{~s}^{-1}$. We note that the addition of CNT from 0.05 to $0.075 \mathrm{wt} \%$ increase the viscosity and plateau is reached at CNT content of $0.1 \mathrm{wt} \%$. At $0.125 \mathrm{wt} \% \mathrm{CNT}$, however, the viscosity is reduced, likely due to the disruption of hydrogen bonding in the TOCNF network by the CNT.

Water vapor interactions. Pristine TOCNF and the respective conductive composite with CNT (TOCNF-CNT) were analyzed at 30-60\% RH in a climatic chamber equipped with a QCM-I probe. The series resonant frequency variations, $\Delta f$, of TOCNF_82 and TOCNF-CNT_96 films at 25, 35 and $50{ }^{\circ} \mathrm{C}$ are presented in Figure 2. Additionally, QCM-I data of the other samples can be seen Figure S4. In a cycle of chamber humidity, following first an increase and then a reduction in $\%$ $\mathrm{RH}$, the series resonant frequency, $f$, registered for the sensor followed a reduction and then an 
increase, respectively. With a basic interpretation, such $\Delta f$ trend in response to the $\% \mathrm{RH}$ is related to the adsorption and desorption of water molecules, i.e. water uptake/release by the films. Notably, both samples show a fast response to changes in \% RH. It should be noted that the frequency responses are highly sensitive. Fast and temporal fluctuations of humidity conditions are easily registered (Figure 2). 

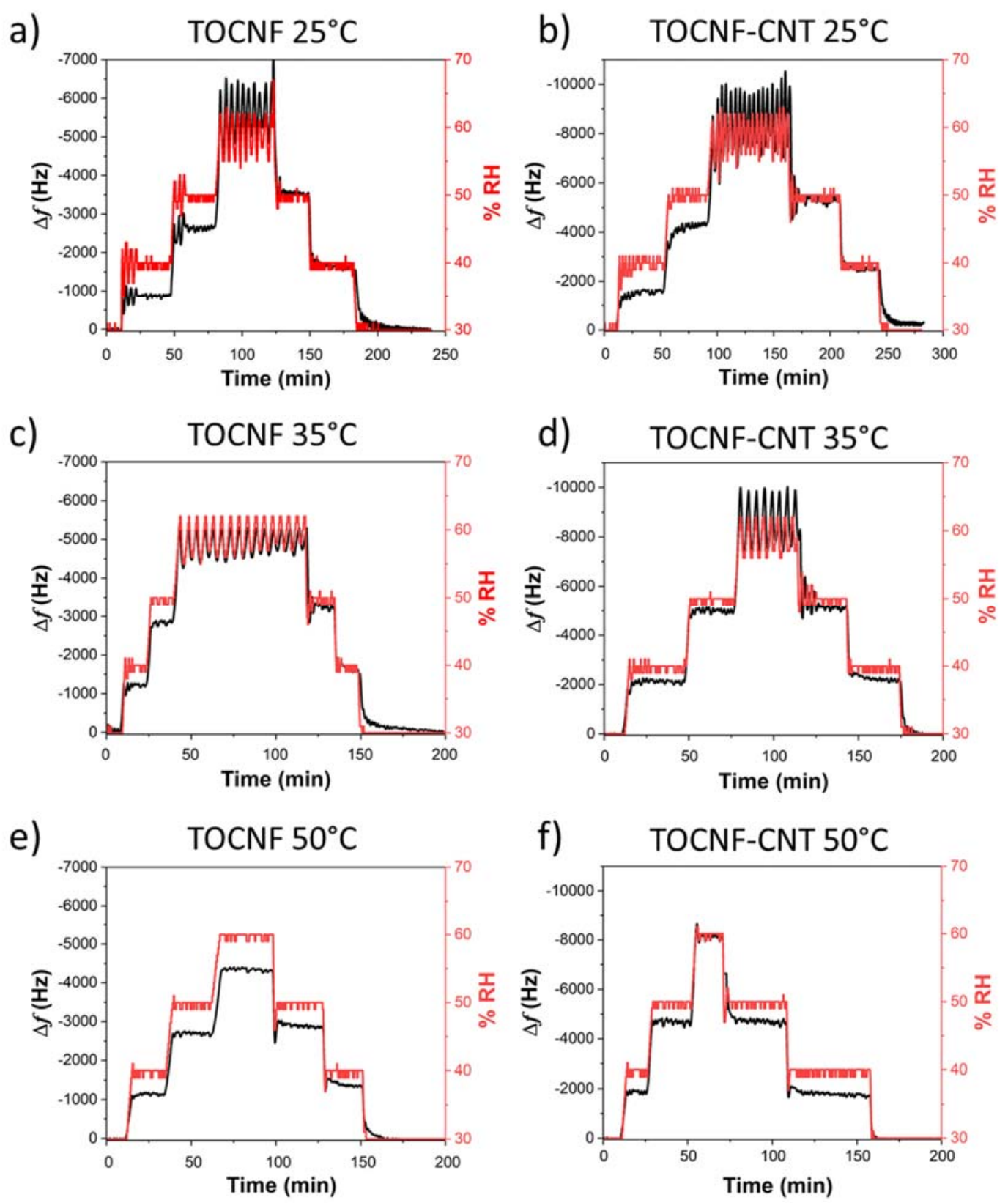

Figure 2. Series resonant frequency changes, $\Delta f$, of the resonators modified with the TOCNF_82 and TOCNF-CNT_96 films exposed to water vapor in the range of 30-60\% RH and 25 (a and b), 35 (c and d) and $50^{\circ} \mathrm{C}(\mathrm{e}$ and $\mathrm{f})$. 
The normalized water sorption results are shown in Figure 3. Figure 3a, b and $\mathbf{c}$ show the normalized frequency changes, $\Delta f$, as a function of $\% \mathrm{RH}$, which correspond to the water adsorption/desorption isotherm. Both TOCNF and TOCNF-CNT composite films exhibit reversible water adsorption/desorption behavior where hysteresis is mostly pronounced at lower temperatures. However, a remarkable increase is observed in the magnitude of normalized frequency changes in the case of TOCNF-CNT composites, which highlights the effect of the altered film morphology (see Figure S5), i.e., its effect on the water sorption behavior. It has been reported that individual TOCNF fibrils do not swell significantly when exposed to humid conditions, but the water molecules penetrate between the nanofibrils and cause swelling of the fibril network ${ }^{8}$. Therefore, we hypothesize that the water sorption in TOCNF and TOCNF-CNT films mainly occurs between the fibrils but not within the fibrils. The addition of CNT and the corresponding disruption of the TOCNF network, make it more accessible to water molecules. The increase in the magnitude of the normalized frequency of TOCNF-CNT, at all temperatures measured, clearly supports our explanation (Figure 3a-c). 

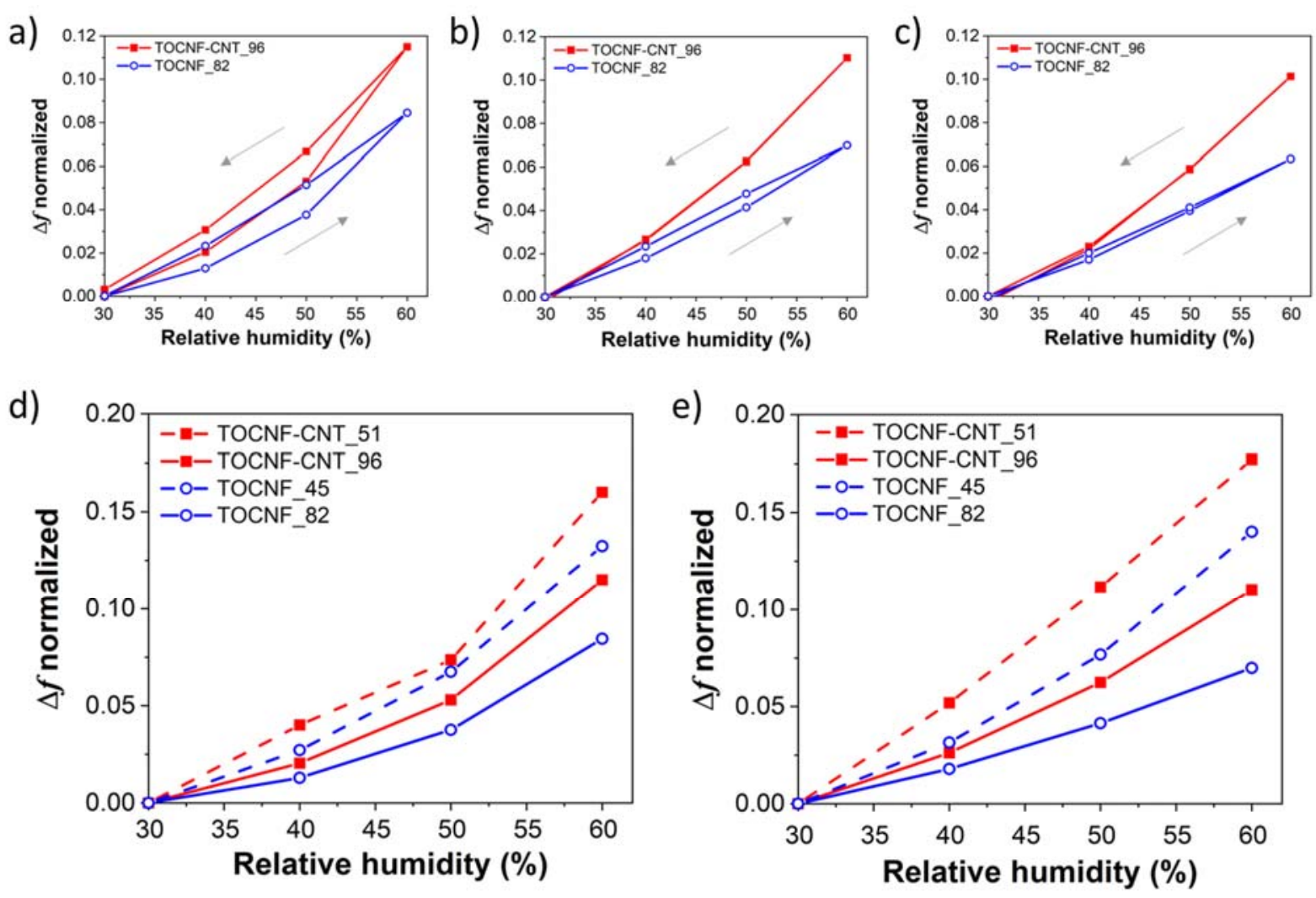

Figure 3. Normalized frequency change, $\Delta f$, during water vapor uptake on TOCNF and TOCNFCNT films: adsorption/desorption curves at a) $25^{\circ} \mathrm{C}$, b) $35^{\circ} \mathrm{C}$, and c) $50{ }^{\circ} \mathrm{C}$, and the effect of films thickness on water adsorption at d) $25{ }^{\circ} \mathrm{C}$ and e) $35{ }^{\circ} \mathrm{C}$. Normalized frequency changes, $\Delta f$, calculated by $\Delta f l\left(f_{\text {loaded quartz, in air }}-f_{\text {bare }}\right.$ quartz, in air $)$.

Regarding the reversibility in the adsorption/desorption isotherms, Figure 3a-c shows that the films return to the original state after the water adsorption/desorption cycle. Only at $25^{\circ} \mathrm{C}$, a small amount of the adsorbed water remains in the films and is not desorbed completely (Figure 3a). Nevertheless, sorption hysteresis can be observed, especially at the lower temperature. At higher temperatures (Figure 3b and c), the sorption hysteresis gradually decreases, which agrees with the 
enhanced dynamics of the kinetic response of the system. It is also noted that the hysteresis almost disappears in the case of the composite films.

We further studied the effects of mass loading in the quartz resonators (which is equivalent to altering the film thickness) on the water vapor adsorption behavior. For both TOCNF and TOCNFCNT films, two loadings were tested (thick films represent twice the loading of the thin films). This effect is illustrated at two different temperatures in Figure $3 \mathbf{d}\left(25^{\circ} \mathrm{C}\right)$ and $\mathbf{e}\left(35^{\circ} \mathrm{C}\right)$. At first glance, the shapes of the curves are analogous, implying that all films qualitatively exhibit similar adsorption response. Drawing on the literature results, the adsorption behavior to TOCNF films is proposed to follow a three-step process ${ }^{15,21}$. In dry air, water molecules associate only on the surface of TOCNF film, while at intermediate humidity $(10-75 \% \mathrm{RH})$, water molecules penetrate the fibril network and form water multilayers. At high humidity levels $(>75 \% \mathrm{RH})$, the water fraction inside the film is significantly increased due to the accumulation of water molecules and their clusters. ${ }^{15}$ Accordingly, water adsorption by nanocellulose films occurs linearly at $0-75 \%$ RH, while it develops exponentially at higher humidity levels ${ }^{15,48}$. The linear water sorption regime can be observed in the isotherms obtained at $35{ }^{\circ} \mathrm{C}$ (Figure 3e). However, at $25{ }^{\circ} \mathrm{C}$, a higher increase in water adsorption is determined between $50-60 \% \mathrm{RH}$, especially in the samples containing CNT (Figure 3d). This indicates that CNT provides better accessibility to water molecules in the cellulose fibril network, resulting in a drastic increase of water content in the TOCNF-CNT films already at lower relative humidity. Additionally, the samples with lower loadings (i.e. thinner films) exhibit significantly higher normalized frequency changes in response to the $\% \mathrm{RH}$ variations, which correlates with a higher amount of water vapor adsorbed compared to the samples with higher loadings (i.e. thicker films). This behavior can be attributed to higher 
water accessibility to the adsorption sites inside the thinner films, due to the shorter diffusion path.

Summary of the QCM-I results can be seen in Table 1.

Table 1. Summarized results of the humidity responsive films on QCM resonators, and glass and paper substrates.

\begin{tabular}{|c|c|c|c|c|c|c|}
\hline \multicolumn{7}{|c|}{ Samples prepared on the PEI-treated gold electrodes of the QCM resonators } \\
\hline Sample name & Active layer & $\begin{array}{c}\text { Ink solids } \\
\text { (wt\%) }\end{array}$ & $\begin{array}{l}\text { Film dry } \\
\text { mass }(\mu \mathrm{g})\end{array}$ & \multicolumn{2}{|c|}{$\begin{array}{c}\Delta \boldsymbol{f}_{\text {normalized }} \\
\text { at } 60 \% \mathrm{RH}\end{array}$} & Comments \\
\hline \multirow[t]{3}{*}{ TOCNF_45 } & \multirow{3}{*}{$\begin{array}{c}\text { TOCNF } \\
\text { suspension }\end{array}$} & \multirow[t]{3}{*}{0.3} & \multirow[t]{3}{*}{45} & $25^{\circ} \mathrm{C}$ & 0.13 & \multirow{3}{*}{$\begin{array}{l}\text { Thinner films } \\
\Delta f_{\text {normalized }} \uparrow\end{array}$} \\
\hline & & & & $35^{\circ} \mathrm{C}$ & 0.14 & \\
\hline & & & & $50^{\circ} \mathrm{C}$ & 0.09 & \\
\hline \multirow{3}{*}{$\begin{array}{l}\text { TOCNF- } \\
\text { CNT_51 }\end{array}$} & \multirow{3}{*}{$\begin{array}{c}\text { TOCNF-CNT } \\
\text { ink }\end{array}$} & \multirow[t]{3}{*}{0.3} & \multirow[t]{3}{*}{51} & $25^{\circ} \mathrm{C}$ & 0.16 & \multirow{3}{*}{$\begin{array}{l}\text { Diffusion length } \\
\text { shorter for water } \\
\text { molecules in } \\
\text { thinner films }\end{array}$} \\
\hline & & & & $35^{\circ} \mathrm{C}$ & 0.18 & \\
\hline & & & & $50^{\circ} \mathrm{C}$ & n.a. & \\
\hline \multirow[t]{3}{*}{ TOCNF_82 } & \multirow{3}{*}{$\begin{array}{c}\text { TOCNF } \\
\text { suspension }\end{array}$} & \multirow[t]{3}{*}{0.5} & \multirow[t]{3}{*}{82} & $25^{\circ} \mathrm{C}$ & 0.08 & \multirow{6}{*}{$\begin{array}{l}\text { CNT addition, } \\
\Delta f_{\text {normalized }} \uparrow \text { for } \\
\text { both lower and } \\
\text { higher loading } \\
\text { samples }\end{array}$} \\
\hline & & & & $35^{\circ} \mathrm{C}$ & 0.07 & \\
\hline & & & & $50^{\circ} \mathrm{C}$ & 0.06 & \\
\hline \multirow{3}{*}{$\begin{array}{l}\text { TOCNF- } \\
\text { CNT_96 }\end{array}$} & \multirow{3}{*}{$\begin{array}{c}\text { TOCNF-CNT } \\
\text { ink }\end{array}$} & \multirow[t]{3}{*}{0.5} & \multirow[t]{3}{*}{96} & $25^{\circ} \mathrm{C}$ & 0.11 & \\
\hline & & & & $35^{\circ} \mathrm{C}$ & 0.11 & \\
\hline & & & & $50^{\circ} \mathrm{C}$ & 0.10 & \\
\hline \multicolumn{7}{|c|}{ Samples prepared on the glass and paper substrates } \\
\hline $\begin{array}{c}\text { Ink CNT } \\
\text { content }(\%)\end{array}$ & $\begin{array}{c}\text { Film } \\
\text { TOCNF:CNT } \\
\text { ratio }\end{array}$ & \multicolumn{2}{|c|}{$\begin{array}{c}\text { Resistance on glass } \\
\text { at } 60 \% \mathrm{RH}, 23^{\circ} \mathrm{C} \\
(\mathrm{k} \Omega)\end{array}$} & \multicolumn{2}{|c|}{$\begin{array}{c}\text { Resistance on paper } \\
\text { at } 60 \% \mathrm{RH}, 23^{\circ} \mathrm{C} \\
(\mathrm{k} \Omega)\end{array}$} & Comments \\
\hline 0.05 & $90: 10$ & \multicolumn{2}{|c|}{$1.7 \pm 0.66$} & \multicolumn{2}{|c|}{$2.3 \pm 0.37$} & $\begin{array}{l}\text { Resistance } \downarrow \text { with } \\
\text { increasing CNT }\end{array}$ \\
\hline 0.075 & $85: 15$ & \multicolumn{2}{|c|}{$0.54 \pm 0.11$} & \multicolumn{2}{|c|}{$0.9 \pm 0.04$} & content \\
\hline 0.1 & $80: 20$ & \multicolumn{2}{|c|}{$0.32 \pm 0.13$} & \multicolumn{2}{|c|}{$0.33 \pm 0.03$} & \\
\hline
\end{tabular}




\begin{tabular}{|l|l|l|l|l|}
\hline 0.125 & $75: 25$ & $0.13 \pm 0.02$ & $0.15 \pm 0.01$ & $\begin{array}{l}\text { Absolute } \\
\text { resistance higher } \\
\text { on paper }\end{array}$ \\
\hline
\end{tabular}

The QCM-I results in Figure 2 and Figure 3 have been discussed in terms of frequency variations in response to the $\% \mathrm{RH}$. If the film to be analyzed is thin and rigid, the decrease in resonant frequency is proportional to an increase in film mass. In this way, the QCM works in the so-called gravimetric regime and the film mass can be calculated using the well-known Sauerbrey equation (Eq. 1). If the film is not "rigid" or not "acoustically thin", further QCM-I analyses are necessary to verify if viscoelastic property changes of the studied films contribute to the overall frequency response. Therefore, the QCM-I results for the measured electroacoustic admittance of the quartz crystal resonator (Figure 1), are analyzed to accurately determine the series resonant frequency, $f$, and damping, $D$. These factors are correlated with the viscoelastic properties of the different tested films, allowing the QCM to work in the non-gravimetric regime.

As a first indicator, the shift in the dissipation factor, $\Delta D$, is estimated using Eq. 2. Figure 4 depicts changes in $\Delta D$ for TOCNF_82 and TOCNF-CNT_96 films in response to the \% RH changes. At lower $\% \mathrm{RH}$ ranges (below $40 \% \mathrm{RH}$ ) and lower temperatures, the $\Delta D$ values are small for the TOCNF films. However, notably higher $\Delta D$ values are observed with increasing $\% \mathrm{RH}$ and temperature, which indicate that the films become softer. This effect is more significant for the TOCNF-CNT_96 film than of the TOCNF_82 film. Most likely, CNT disrupts the formation of the nanocellulose fibril network, leading to a looser fibril packing compared to that of the pristine nanocellulose film (Figure 4). 

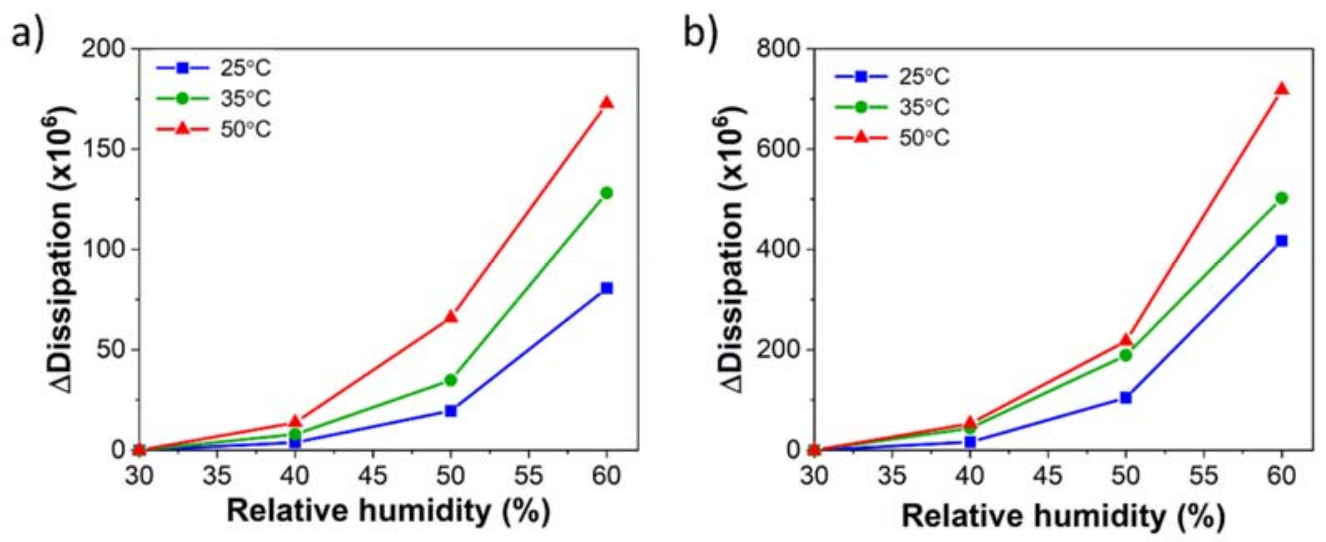

Figure 4. Changes in dissipation factor, $\Delta D$, of a) TOCNF_82 and b) TOCNF-CNT_96 films deposited on the gold electrode of the resonator. The data are obtained from the measurements performed at three different temperatures and in the \% RH range between 30 and $60 \%$.

A deeper investigation of possible viscoelastic property changes of the films during water vapor exposure at different temperatures is performed by analyzing QCM-I data. Viscoelastic model of Martin-Granstaff ${ }^{33}$ is used and a fitting procedure is employed by comparison betwe0en the experimental electroacoustic admittance, $Y_{\exp }(\omega)$, data (Figure 1 shows an example) and theoretical expressions, $Y_{t h}^{V}(\omega)$ (Eq. 3-6, see the experimental part for details). This fitting procedure provided the storage modulus, $\mu f$, (related to the rigidity), the viscosity, $\eta_{f}$, and density, $\rho f$, of the film to be estimated, while the film thickness is kept constant $\left(h_{f}=2.13 \mu \mathrm{m}\right)$. It is noted that keeping either $\rho_{f}$ or $h_{f}$ constant in the fitting with the viscoelastic model is a general procedure, as described earlier ${ }^{49}$.

The results of TOCNF_82 and TOCNF_96 films at $25^{\circ} \mathrm{C}$ as a function of $\%$ RH are presented in Figure S6. Higher storage modulus, $\mu$, and lower viscosity, $\eta_{f}$, values of the pristine TOCNF_82 film (Figure S6a) compared with those of the composite film, TOCNF-CNT_96 (Figure S6b), indicates a higher rigidity degree in the case of the pristine film. But for both films, there is a 
dependence on the film viscosity, $\eta_{f}$, which is more evident at higher $\%$ RH values. Then, by using the film $\rho_{f}$ and thickness (in Figure S6), the $\Delta m$ was estimated, hereafter referred to as $\Delta m_{M a r t i n-}$ Granstaff, (see Figure 5). The $\Delta m_{\text {Sauerbrey }}$ estimated by converting the $\Delta f$ (using data in Figure 2a and b) using the Sauerbrey equation (Eq. 1) is given as a comparison in the plots shown in Figure 5. The two models result in relatively similar mass estimations but only at low \% RH. Differences exist at high \% RH. With the Martin-Granstaff model, the maximum adsorption $\left(25^{\circ} \mathrm{C}\right)$ onto TOCNF-CNT_96 and TOCNF_82 films are $120 \mu \mathrm{g} / \mathrm{cm}^{2}$ and $12 \mu \mathrm{g} / \mathrm{cm}^{2}$, respectively. Using the Sauerbrey equation, the corresponding maximum adsorption values at the same temperature are $52 \mu \mathrm{g} / \mathrm{cm}^{2}$ and $34 \mu \mathrm{g} / \mathrm{cm}^{2}$. It is noted that the "rigid" assumption in terms of $\Delta m$ Sauerbrey overestimates and underestimates the AmMartin-Granstaff for the pristine (TOCNF_82) and the composite film (TOCNF-CNT_96), respectively.
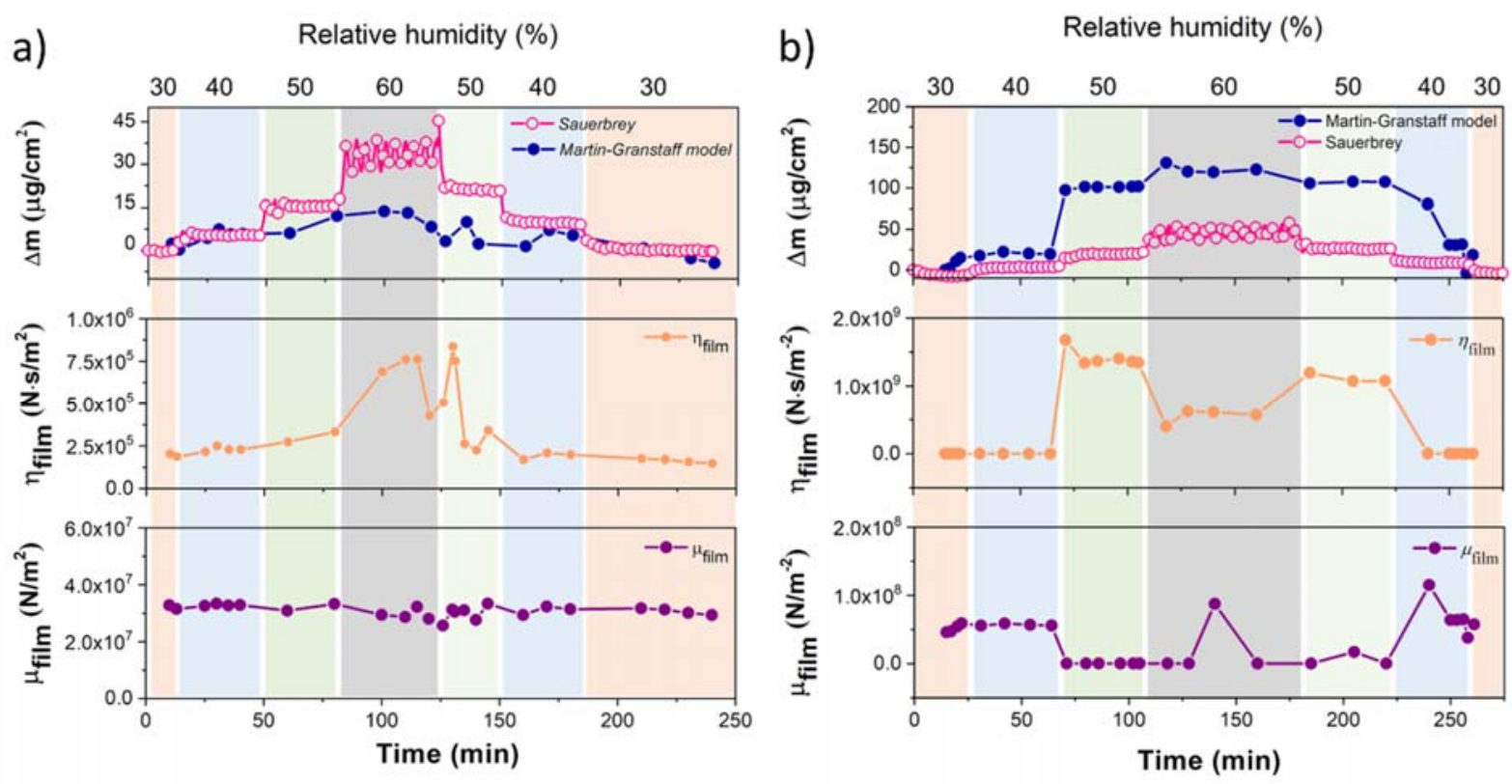

Figure 5. Estimation of the changes in mass, viscosity and storage modulus of a) TOCNF_82, b) TOCNF-CNT_96 films at $25{ }^{\circ} \mathrm{C}$ and as a function of $\%$ RH, obtained by the Martin-Granstaff 
model. The $\Delta m$ estimated by converting the $\Delta f$ using the Sauerbrey equation (Eq. 1 ) is given for comparison.

The results presented in Figure 5 are in agreement with the related findings found in the literature. Specifically, for the QCM response with thin viscoelastic films, it has been shown that the film mass induces an increased dissipation, and can be in fact overestimated by the Sauerbrey approach $^{50,51}$. Such cases occur when the elastic component of the film, $\mu_{f}$, dominates over the viscous one, $\eta_{f}$, (i.e. if $\left.\left(\eta_{f} / \mu_{f}\right)<\sim 1\right)$, which is the case in Figure 5a. On the other hand, the mass is underestimated if the viscous component dominates, which is the case in Figure 5b. Höök et al. ${ }^{50}$ explained this in terms of the dynamic mass, i.e., the mass actually sensed during the periodic oscillation, which can become either larger or smaller than the static mass, depending on the combination of thickness, elastic modulus, and viscosity. However, it is important to note that the Sauerbrey equation can be used even for viscoelastic films, when examined in air, under the condition that $\left(\eta_{f} / \mu_{f}\right)$ is close to 1 . In our case, $\left(\eta_{f} / \mu_{f}\right)<\sim 1$ for the pristine TOCNF_82 and $\left(\eta_{f} / \mu_{f}\right)$ $>\sim 1$ for the composite film (TOCNF-CNT_96), thus, the use of the Martin-Granstaff viscoelastic model $^{33}$ is justified. Overall, a significant increase in film viscosity (Figure 5) and the dissipation factor of the sensor (Figure 4) are observed during water vapor uptake (at high \% RH). Hence, it is concluded that the viscoelastic model gives more accurate estimations of the mass increase during water vapor exposure. By using the viscoelastic model, a mass increase of $20 \%$ and $3.7 \%$ are obtained for TOCNF-CNT_96 and TOCNF_82 films, respectively, during water uptake. Furthermore, our analysis reveals that the TOCNF-based films become soft and viscoelastic during water uptake, and this is more pronounced in the presence of CNT. 
Electrical conductivity and performance in humidity sensing. The conductive nanocellulosic composites (TOCNF-CNT) adhered to glass substrates were studied for their response to humidity. The electrical conductivity of dried TOCNF-CNT patterns was investigated for various thicknesses and dimensions to reach the window of operation, suitable for humidity sensing. The sheet resistances of conductive patterns with different thicknesses (three different ink volumes were deposited, corresponding to three different thicknesses) can be seen in Figure 6a. Notably, sheet resistance decreases with increasing the film thickness and CNT content. Hence, a higher amount of CNT for a given area improves the ability to carry electric charges. As observed earlier from the QCM-I results (Figure 3d and e), the thickness of the film affects water sorption, and thus, its sensitivity to humidity. Figure $\mathbf{6 b}$ shows changes in film resistance as a function of $\%$ RH. When the films are exposed to higher humidity, the resistance values increase. This is because the hydrophilic TOCNF fibril network swells at higher humidity, causing fewer contacts between CNTs, which increases the electrical resistance. As can be seen, the thickest film ( $1 \mathrm{ml}$ ink volume) undergoes more limited changes in resistance at given \% RH compared to that of the thinner films. This is because of the longer diffusion path for water molecules inside the thickest film, resulting in slower film swelling. Thus, despite the better conductivity, the thick films present lower sensitivity to humidity changes, in agreement with the QCM-I (Figure 3d and e). The effect of film dimensions on resistance can be seen in Figure 6c. When the measurement distance increases from 1.5 to $5.5 \mathrm{~cm}$, the resistance values increases, due to longer distance from one probe to the other. 

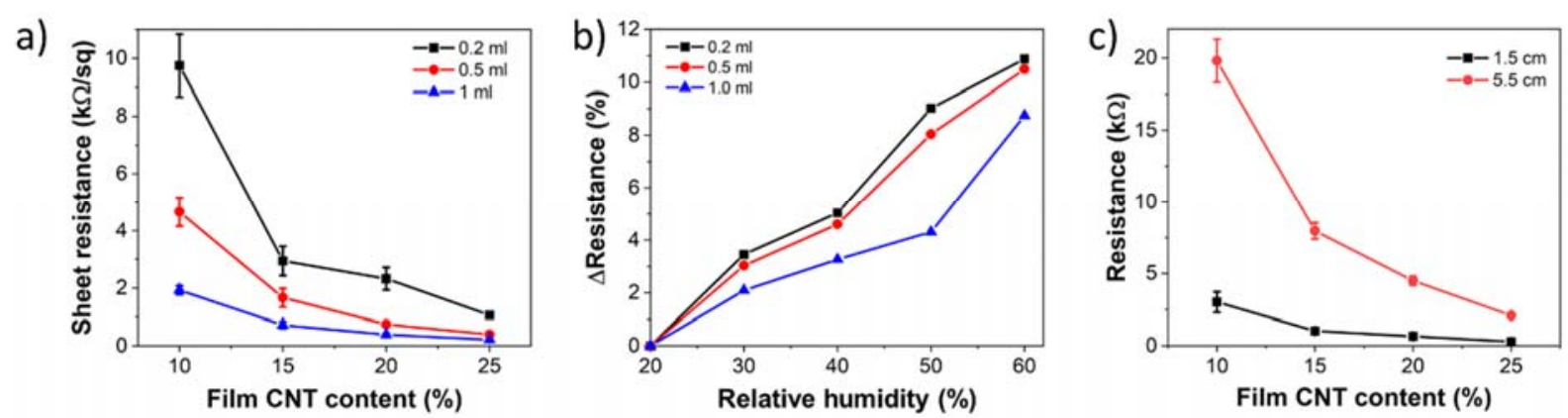

Figure 6. Electrical conductivity profiles measured on glass substrates: effect of film thickness (three different ink volumes deposited, corresponding to three different thickness) on a) sheet resistance, and $\mathrm{b}$ ) changes in resistance at different $\% \mathrm{RH}$ (sample with $10 \mathrm{wt} \% \mathrm{CNT}$ ). The effect of the probe separation distance of a two-probe multimeter ( film dimensions) and CNT content on c) resistance (thickness with $0.5 \mathrm{ml}$ ink).

To test the humidity sensing performance, sensors were prepared by coating inks $(0.3 \mathrm{ml})$ on glass and paper (PowerCoat ${ }^{\circledR} \mathrm{HD}$ ) substrates using a fixed area of $1.5 \mathrm{~cm} \times 1.5 \mathrm{~cm}$. The resistance of the sensors was measured in the humidity chamber at $23{ }^{\circ} \mathrm{C}$. Figure 7 shows the profiles of humidity sensitivity in sensors with various CNT content (10-25\% in dry mass), on glass and paper substrates. All samples, deposited on glass or paper, follow a similar trend. A non-linear increase in resistance occurs between 50-60\% RH, which agrees well with the results obtained with QCMI (Figure 3d). Specifically, the film swelling and softening are higher at 50-60\% RH (Figure 5), which contributes to higher resistance change. In addition, the CNT content affects sensitivity. Interestingly, sensors with lower CNT content are more sensitive. The conductive particles can be packed close to each other in films of high CNT content, and despite the swelling, the contacts between CNTs are not affected significantly. SEM images of the samples with varying CNT content are included in Figure S7, showing increased CNT packing with increased loading. 
However, the CNT content should not be too low, thus, optimal loading is required. Films with lower CNT content (5 wt\%) show poor sensitivity due to high resistance hysteresis at higher \% RH. An optimization effort led to the conclusion that the sensor with $10 \mathrm{wt} \%$ CNT loading has the best humidity response (highest sensitivity).
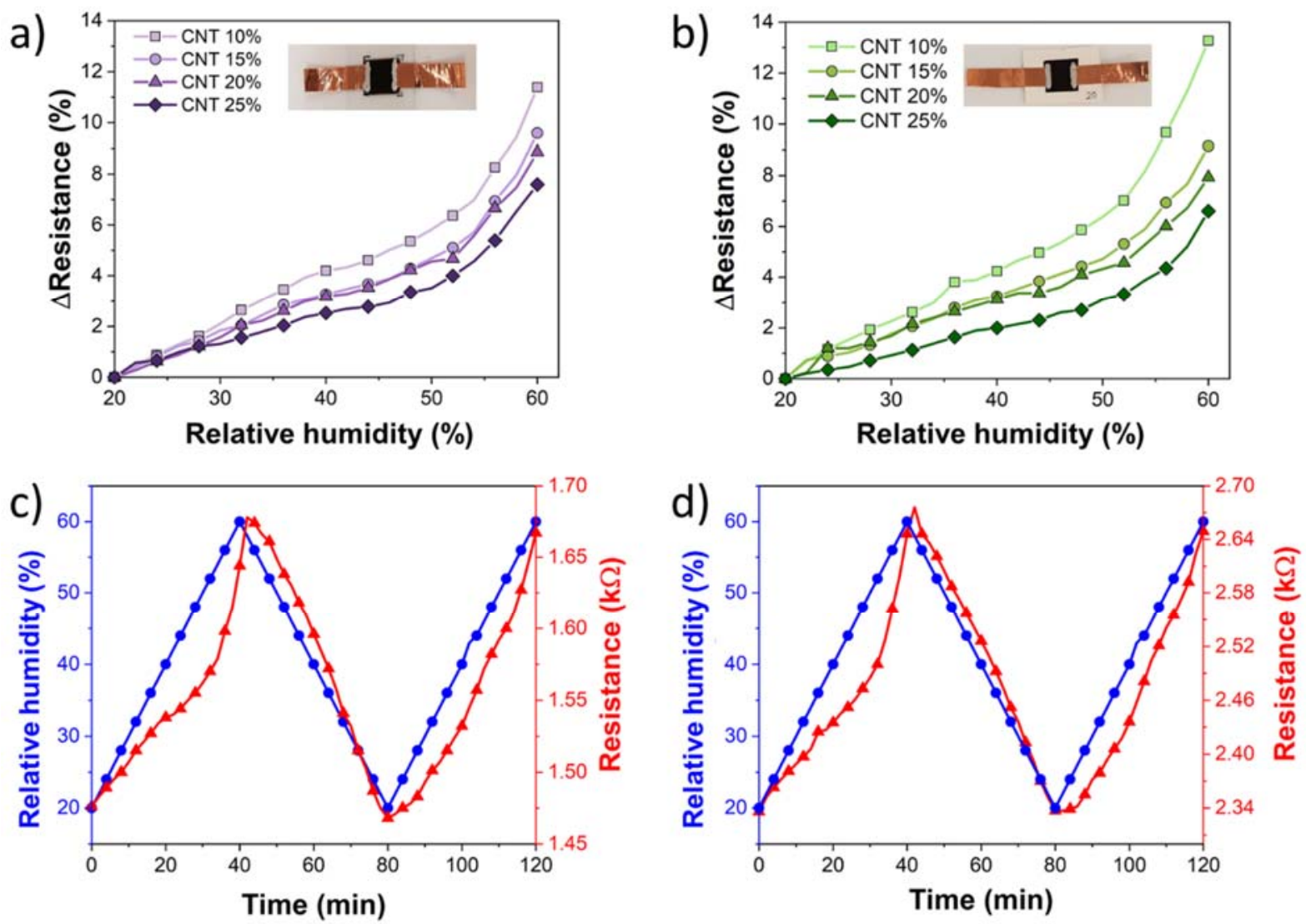

Figure 7. Results for humidity sensing performed on glass and paper substrates: resistance variation as a function of $\% \mathrm{RH}$ on a) glass and b) paper, and sensitivity tests with films with $10 \%$ CNT loading on c) glass and d) paper.

The resistance profiles recorded for sensors deposited on glass and paper reveal the effect of substrate material on humidity sensing (Figure 7c, d). The absolute resistance is higher on paper than on glass (see Table 1), but the humidity response is very similar as measured on both 
substrates. The corresponding resistance of the conductive films deposited on glass and paper substrates increases by $13.7 \%$ and $14.6 \%$, going from 20 to $60 \% \mathrm{RH}$, respectively. The results indicate that swelling of paper does not have a significant effect on the sensor sensitivity. The surface structures of the paper substrate and sensor $(10 \mathrm{wt} \% \mathrm{CNT})$ deposited on paper are shown in Figure S8.

Adhesion to paper and durability. Coating of the aqueous ink on paper was challenging due to the low surface energy of the smooth side of the material, which is coated with a polymer layer (Figure S9a). The tape test indicated a weak adhesion of the dried film to untreated paper (Figure 8a). To improve the adhesion quality, different surface treatments were performed on the substrate. Plasma treatment was found to improve ink coating uniformity (Figure S9b), but the adhesion of the dried film was not significantly improved (Figure 8b). Application of a cationic surfactant (CTAB) improved ink coating and dried film adhesion (Figure S9c, Figure 8c). Additionally, improvements are gained if a combination of plasma and surfactant treatments are carried out (Figure S9d, Figure 8d). 

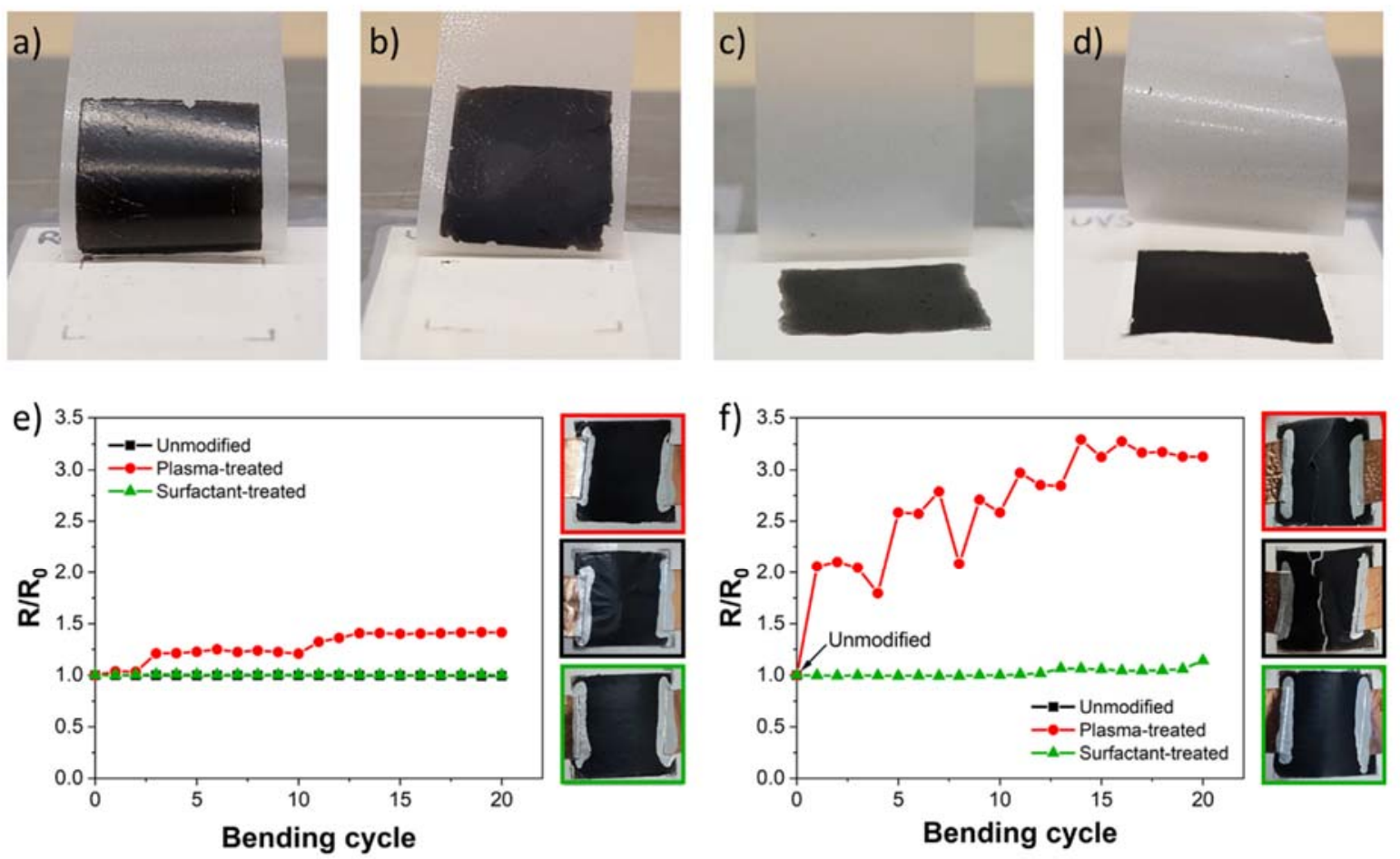

Figure 8. Adhesion of dried TOCNF-CNT films on paper substrates: a) unmodified, b) plasmatreated, c) surfactant-treated, and d) plasma- and surfactant-treated. Normalized resistance as a function of bending cycles with e) $1.45 \mathrm{~cm}$ and f) $0.55 \mathrm{~cm}$ bending radius, showing the effect of surface treatments on sensor performance and durability.

Bending tests were performed to study the effect of surface treatment on the flexibility and durability of the humidity sensor. Figure 8e and $\mathbf{f}$ show the normalized resistance of the sensors after each tensile bend (1.45 and $0.55 \mathrm{~cm}$ bending radius). Figure 8e shows the effect of a larger bending radius $(1.45 \mathrm{~cm})$ on the sensor performance. The resistance values of the unmodified and surfactant-treated substrates remain similar after 20 bending cycles. However, detachment of the conductive film from the unmodified substrate occurs. A two-step increase in the values of sensor resistance is noted for the plasma-treated substrate after 20 bending cycles. Possibly, some 
microscale cracks are formed during bending. Additionally, compression bending results (Figure S10) show that only small resistance variations occur when the system is exposed to compressive bending. Figure $8 \mathbf{f}$ shows the tensile bending results obtained with a smaller bending radius $(0.55$ $\mathrm{cm})$. A clear reduction in performance is noted when the unmodified system is subjected to extensive tensile bending (using a small bending radius). It can be observed that cracks appear immediately after the first bend for the unmodified paper. For the plasma-treated substrate, the sensor experiences gradual damaging with bending cycles. Interestingly, between some bends, a decrease in resistance is observed, which is suggested to be the result of CNT reorganization. Specifically, bending causes CNT alignment inside the fibril network, creating more connections and resulting in the reduction of electrical resistance. A remarkable improvement is observed for the sensor adhered on the surfactant-treated substrate, which was not affected by bending. The resistance values of the surfactant-treated sample are similar after each bending, with no observable damage to the conductive film (Figure 8f).

Producing tailored papers and incorporating cellulose in inks is relevant in the development of biobased electronic systems including printed sensors, batteries, circuits and displays ${ }^{52}$. Here, the composite inks and derived sensing thin films show that cellulosic materials could be used not only as substrate but also as an active component in electronic systems, offering the potential to replace some of the traditionally used, non-green components in electronic devices. These TOCNF-based sensors offer especially potential to develop cold-chain monitoring smart-labels applicable in tracking the state of food or pharmaceutical products during their transport and storage. In addition to smart labels, these devices could be used in industries such as biomedical, food processing, pharmaceuticals, microelectronics, agriculture, and structural health monitoring ${ }^{53}$. 


\section{CONCLUSIONS}

Conductive inks comprising cellulose nanofibrils (TOCNF) and minor loadings of carbon nanotubes (CNT) were used in the synthesis of humidity sensors for uses on paper and glass substrates. Water vapor sorption phenomena on the conductive films were conducted using a climatic chamber equipped with a QCM-I probe. The films showed fast responses to changes in $\% \mathrm{RH}$, and with water sorption equivalent to $20 \%$ mass increase recorded at $60 \% \mathrm{RH}$ and $25{ }^{\circ} \mathrm{C}$. The Martin-Granstaff viscoelastic model confirmed the viscoelastic changes of the films in the presence of CNT during water uptake. The humidity response of the conductive nanocellulose films was measured, indicating a non-linear dependence on $\% \mathrm{RH}$ at $20-60 \% \mathrm{RH}$ and $23{ }^{\circ} \mathrm{C}$, in agreement with the QCM-I results. Low CNT loading showed enhanced sensitivity to changes in humidity. Any possible swelling of the paper substrate did not affect the performance of the humidity sensors. The adhesion and resistance to bending of the proposed sensors point to their possible application as humidity sensors for biobased smart labels and intelligent packaging.

\section{ASSOCIATED CONTENT}

Supporting Information. Additional information is provided online at the website, which includes:

Schematic illustrations of the tensile and compression bending tests, rheological properties of the conductive inks, XPS spectra for unmodified and oxidized CNT, SEM images of the TOCNF and TOCNF-CNT films on top of QCM resonators, changes in the density of TOCNF and TOCNF-CNT films during water uptake, SEM images of the unmodified 
substrate and humidity sensors with different CNT loading, wet ink adhesion on unmodified and treated paper, and the effect of compressive bending on sensors.

\section{AUTHOR INFORMATION}

\section{Corresponding Author}

*E-mail: orlando.rojas@,aalto.fi

*E-mail: ozlem.sel@upmc.fr

\section{Author Contributions}

The manuscript was written through contributions of all authors. All authors have given approval to the final version of the manuscript.

\section{ACKNOWLEDGMENT}

This project has received funding from the European Union's Horizon 2020 research and innovation programme under grant agreement No 760876. This work was a part of the Academy of Finland's Flagship Programme under Projects No. 318890 and 318891 (Competence Center for Materials Bioeconomy, FinnCERES). The LISE laboratory UMR8235 of Sorbonne University, Paris, France is acknowledged for access to QCM-I instrumentation. Katariina Solin acknowledges funding by the Aalto University School of Chemical Engineering doctoral programme. We acknowledge the provision of facilities and technical support by Aalto University at OtaNano Nanomicroscopy Center (Aalto-NMC). Finally, OJR acknowledges funding from the European 
Research Council (ERC) under the European Union's Horizon 2020 research and innovation program (ERC Advanced Grant Agreement No. 788489, "BioElCell”), the Canada Excellence Research Chair initiative and the Canada Foundation for Innovation (CFI).

\section{REFERENCES}

(1) Voisin, H.; Bergström, L.; Liu, P.; Mathew, A. P. Nanocellulose-Based Materials for Water Purification. Nanomaterials 2017, 7 (3), 1-18. https://doi.org/10.3390/nano7030057.

(2) Sharma, P. R.; Sharma, S. K.; Lindström, T.; Hsiao, B. S. Nanocellulose-Enabled Membranes for Water Purification: Perspectives. Adv. Sustain. Syst. 2020, 4, 1900114. https://doi.org/10.1002/adsu.201900114.

(3) Barras, R.; Cunha, I.; Gaspar, D.; Fortunato, E.; Martins, R.; Pereira, L. Printable CelluloseBased Electroconductive Composites for Sensing Elements in Paper Electronics. Flex. Print. Electron. 2017, 2 (1), 1-12. https://doi.org/10.1088/2058-8585/aa5ef9.

(4) Zhu, P.; Liu, Y.; Fang, Z.; Kuang, Y.; Zhang, Y.; Peng, C.; Chen, G. Flexible and Highly Sensitive Humidity Sensor Based on Cellulose Nanofibers and Carbon Nanotube Composite Film. Langmuir 2019, $35 \quad$ (14), 4834-4842. https://doi.org/10.1021/acs.langmuir.8b04259.

(5) Lindman, B.; Karlström, G.; Stigsson, L. On the Mechanism of Dissolution of Cellulose. J. Mol. Liq. 2010, 156 (1), 76-81. https://doi.org/10.1016/j.molliq.2010.04.016.

(6) Johansson, L. S.; Tammelin, T.; Campbell, J. M.; Setälä, H.; Österberg, M. Experimental Evidence on Medium Driven Cellulose Surface Adaptation Demonstrated Using Nanofibrillated Cellulose. Soft Matter 2011, $7 \quad$ (22), 10917-10924. 
https://doi.org/10.1039/c1sm06073b.

(7) Isogai, A.; Kato, Y. Preparation of Polyuronic Acid from Cellulose by TEMPO-Mediated Oxidation. Cellulose 1998, 5 (3), 153-164. https://doi.org/10.1023/A:1009208603673.

(8) Hakalahti, M. Cellulose Nanofibril Films as Bioinspired Membranes - Capitalizing on Water Interactions, Aalto University, Espoo, Finland, 2018.

(9) Piringer, O.-G.; Baner, A. L. Plastic Packaging Materials for Food: Barrier Function, Mass Transport, Quality Assurance, and Legislation; Wiley-VCH, 2000.

(10) Belbekhouche, S.; Bras, J.; Siqueira, G.; Chappey, C.; Lebrun, L.; Khelifi, B.; Marais, S.; Dufresne, A. Water Sorption Behavior and Gas Barrier Properties of Cellulose Whiskers and Microfibrils Films. Carbohydr. Polym. 2011, 83 (4), 1740-1748. https://doi.org/10.1016/j.carbpol.2010.10.036.

(11) Dutcher, C. S.; Ge, X.; Wexler, A. S.; Clegg, S. L. Statistical Mechanics of Multilayer Sorption: Extension of the Brunauer-Emmett-Teller (BET) and Guggenheim-Anderson-de Boer (GAB) Adsorption Isotherms. J. Phys. Chem. C 2011, 115 (33), 16474-16487. https://doi.org/10.1021/jp203879d.

(12) Hailwood, A. J.; Horrobin, S. Absorption of Water by Polymers: Analysis in Terms of a Simple Model. Trans. Faraday Soc. 1946, $42 \quad$ (0), $\quad$ B084. https://doi.org/10.1039/TF946420B084.

(13) Driemeier, C.; Mendes, F. M.; Oliveira, M. M. Dynamic Vapor Sorption and Thermoporometry to Probe Water in Celluloses. Cellulose 2012, 19 (4), 1051-1063. https://doi.org/10.1007/s10570-012-9727-z.

(14) Gouanvé, F.; Marais, S.; Bessadok, A.; Langevin, D.; Morvan, C.; Métayer, M. Study of Water Sorption in Modified Flax Fibers. J. Appl. Polym. Sci. 2006, 101 (6), 4281-4289. 
https://doi.org/10.1002/app.23661.

(15) Hakalahti, M.; Faustini, M.; Boissière, C.; Kontturi, E.; Tammelin, T. Interfacial Mechanisms of Water Vapor Sorption into Cellulose Nanofibril Films as Revealed by Quantitative Models. Biomacromolecules 2017, $18 \quad$ (9), 2951-2958. https://doi.org/10.1021/acs.biomac.7b00890.

(16) Langmuir, I. The Adsorption of Gases on Plane Surfaces of Glass, Mica and Platinum. $J$. Am. Chem. Soc. 1918, 40 (9), 1361-1403. https://doi.org/10.1021/ja02242a004.

(17) Henry, W. III. Experiments on the Quantity of Gases Absorbed by Water, at Different Temperatures, and under Different Pressures. Philos. Trans. R. Soc. London 1803, 93, 29 274. https://doi.org/10.1098/rstl.1803.0004.

(18) Flory, P. J. Principles of Polymer Chemistry; Cornell University Press: Ithaca, NY, 1953.

(19) Lundahl, M. J.; Cunha, A. G.; Rojo, E.; Papageorgiou, A. C.; Rautkari, L.; Arboleda, J. C.; Rojas, O. J. Strength and Water Interactions of Cellulose Filaments Wet-Spun from Cellulose Nanofibril Hydrogels. Sci. Rep. 2016, $6 \quad$ (1), 1-13. https://doi.org/10.1038/srep30695.

(20) Wang, L.; Lundahl, M. J.; Greca, L. G.; Papageorgiou, A. C.; Borghei, M.; Rojas, O. J. Effects of Non-Solvents and Electrolytes on the Formation and Properties of Cellulose I Filaments. Sci. Rep. 2019, 9 (1), 1-11. https://doi.org/10.1038/s41598-019-53215-0.

(21) Tammelin, T.; Abburi, R.; Gestranius, M.; Laine, C.; Setälä, H.; Österberg, M. Correlation between Cellulose Thin Film Supramolecular Structures and Interactions with Water. Soft Matter 2015, 11 (21), 4273-4282. https://doi.org/10.1039/c5sm00374a.

(22) Rianjanu, A.; Julian, T.; Hidayat, S. N.; Yulianto, N.; Majid, N.; Syamsu, I.; Wasisto, H. S.; Triyana, K. Quartz Crystal Microbalance Humidity Sensors Integrated with Hydrophilic 
Polyethyleneimine-Grafted Polyacrylonitrile Nanofibers. Sensors Actuators, B Chem. 2020, 319, 1-13. https://doi.org/10.1016/j.snb.2020.128286.

(23) Martins, R.; Ferreira, I.; Fortunato, E. Electronics with and on Paper. Phys. Status Solidi Rapid Res. Lett. 2011, 5 (9), 332-335. https://doi.org/10.1002/pssr.201105247.

(24) Vicente, A. T.; Araújo, A.; Mendes, M. J.; Nunes, D.; Oliveira, M. J.; Sanchez-Sobrado, O.; Ferreira, M. P.; Águas, H.; Fortunato, E.; Martins, R. Multifunctional Cellulose-Paper for Light Harvesting and Smart Sensing Applications. Journal of Materials Chemistry C. Royal Society of Chemistry March 29, 2018, pp 3143-3181. https://doi.org/10.1039/c7tc05271e.

(25) Hou, L.; Zhao, H.; Bi, S.; Zhu, L.; Xu, Y.; Lu, Y. Ultrasensitive and Highly Flexible Nonenzymatic Glucose Biosensor Based on Laser-Scribed Carbon Paper Substrate. Appl. Surf. Sci. 2019, 465, 320-331. https://doi.org/10.1016/j.apsusc.2018.09.166.

(26) Mraović, M.; Muck, T.; Pivar, M.; Trontelj, J.; Pleteršek, A. Humidity Sensors Printed on Recycled Paper and Cardboard. Sensors (Switzerland) 2014, 14 (8), 13628-13643. https://doi.org/10.3390/s140813628.

(27) Mahadeva, S. K.; Yun, S.; Kim, J. Flexible Humidity and Temperature Sensor Based on Cellulose-Polypyrrole Nanocomposite. Sensors Actuators, A Phys. 2011, 165 (2), 194-199. https://doi.org/10.1016/j.sna.2010.10.018.

(28) Han, J. W.; Kim, B.; Li, J.; Meyyappan, M. Carbon Nanotube Based Humidity Sensor on Cellulose Paper. J. Phys. Chem. C 2012, 116 (41), 22094-22097. https://doi.org/10.1021/jp3080223.

(29) Feng, Y.; Xie, L.; Chen, Q.; Zheng, L. R. Low-Cost Printed Chipless RFID Humidity Sensor Tag for Intelligent Packaging. IEEE Sens. J. 2015, 15 (6), 3201-3208. https://doi.org/10.1109/JSEN.2014.2385154. 
(30) Syrový, T.; Maronová, S.; Kuberský, P.; Ehman, N. V.; Vallejos, M. E.; Pretl, S.; Felissia, F. E.; Area, M. C.; Chinga Carrasco, G. Wide Range Humidity Sensors Printed on Biocomposite Films of Cellulose Nanofibril and Poly(Ethylene Glycol). J. Appl. Polym. Sci. 2019, 136 (36), 47920. https://doi.org/10.1002/app.47920.

(31) Kotresh, S.; Ravikiran, Y. T.; Raj Prakash, H. G.; Ramana, C. V. V.; Vijayakumari, S. C.; Thomas, S. Humidity Sensing Performance of Spin Coated Polyaniline-Carboxymethyl Cellulose Composite at Room Temperature. Cellulose 2016, 23 (5), 3177-3186. https://doi.org/10.1007/s10570-016-1035-6.

(32) Sauerbrey, G. Verwendung von Schwingquarzen Zur Wägung Dünner Schichten Und Zur Mikrowägung. Zeitschrift für Phys. 1959, $155 \quad$ (2), 206-222. https://doi.org/10.1007/BF01337937.

(33) Granstaff, V. E.; Martin, S. J. Characterization of a Thickness-Shear Mode Quartz Resonator with Multiple Nonpiezoelectric Layers. J. Appl. Phys. 1994, 75 (3), 1319-1329. https://doi.org/10.1063/1.356410.

(34) Orelma, H.; Vuoriluoto, M.; Johansson, L. S.; Campbell, J. M.; Filpponen, I.; Biesalski, M.; Rojas, O. J. Preparation of Photoreactive Nanocellulosic Materials: Via Benzophenone Grafting. $R S C A d v$. 2016, 6 (88), 85100-85106. https://doi.org/10.1039/c6ra15015b.

(35) PowerCoat ${ }^{\circledR}$ HD $\quad-\quad$ Arjowiggins $\quad$ Creative Papers https://powercoatpaper.com/products/powercoat-hd/ (accessed Apr 3, 2020).

(36) Andersen, S. M.; Borghei, M.; Dhiman, R.; Jiang, H.; Ruiz, V.; Kauppinen, E.; Skou, E. Interaction of Multi-Walled Carbon Nanotubes with Perfluorinated Sulfonic Acid Ionomers and Surface Treatment Studies. Carbon N. Y. 2014, 71, 218-228. https://doi.org/10.1016/J.CARBON.2014.01.032. 
(37) Johansson, L.; Campbell, J. M.; Rojas, O. J. Cellulose as the in Situ Reference for Organic XPS. Why? Because It Works. Surf. Interface Anal. 2020, sia.6759. https://doi.org/10.1002/sia.6759.

(38) Bizet, K.; Gabrielli, C.; Perrot, H. Immunodetection by Quartz Crystal Microbalance: A New Approach for Direct Detection of Rabbit IgG and Peroxidase. Appl. Biochem. Biotechnol. - Part A Enzym. Eng. Biotechnol. 2000, 89 (139), 139-149. https://doi.org/10.1385/ABAB:89:2-3:139.

(39) Gao, W.; Debiemme-Chouvy, C.; Lahcini, M.; Perrot, H.; Sel, O. Tuning Charge Storage Properties of Supercapacitive Electrodes Evidenced by In Situ Gravimetric and Viscoelastic Explorations. Anal. Chem. 2019, $91 \quad$ (4), 2885-2893. https://doi.org/10.1021/acs.analchem.8b04886.

(40) García-Jareño, J. J.; Gabrielli, C.; Perrot, H. Validation of the Mass Response of a Quartz Crystal Microbalance Coated with Prussian Blue Film for Ac Electrogravimetry. Electrochem. commun. 2000, 2 (3), 195-200. https://doi.org/10.1016/S13882481(99)00168-X.

(41) Vadgama, P. Surfaces and Interfaces for Biomaterials; Woodhead Pub, 2005. https://doi.org/10.1533/9781845690809.

(42) Mohan, T.; Niegelhell, K.; Zarth, C. S. P.; Kargl, R.; Köstler, S.; Ribitsch, V.; Heinze, T.; Spirk, S.; Stana-Kleinschek, K. Triggering Protein Adsorption on Tailored Cationic Cellulose Surfaces. Biomacromolecules 2014, $15 \quad$ (11), 3931-3941. https://doi.org/10.1021/bm500997s.

(43) Kravchenko, S.; Snopok, B. "Vanishing Mass" in the Sauerbrey World: Quartz Crystal Microbalance Study of Self-Assembled Monolayers Based on a Tripod-Branched Structure 
with Tuneable Molecular Flexibility. Analyst 2020, 145 (2), 656-666. https://doi.org/10.1039/c9an01366k.

(44) Arnau, A.; Soares, D. Fundamentals of Piezoelectricity. In Piezoelectric Transducers and Applications; Springer Berlin Heidelberg, 2008; pp 1-38. https://doi.org/10.1007/978-3540-77508-9_1.

(45) Hashmi, S. G.; Halme, J.; Ma, Y.; Saukkonen, T.; Lund, P. A Single-Walled Carbon Nanotube Coated Flexible PVC Counter Electrode for Dye-Sensitized Solar Cells. Adv. Mater. Interfaces 2014, 1 (2), 1-6. https://doi.org/10.1002/admi.201300055.

(46) Hashmi, S. G.; Moehl, T.; Halme, J.; Ma, Y.; Saukkonen, T.; Yella, A.; Giordano, F.; Decoppet, J. D.; Zakeeruddin, S. M.; Lund, P.; et al. A Durable SWCNT/PET Polymer Foil Based Metal Free Counter Electrode for Flexible Dye-Sensitized Solar Cells. J. Mater. Chem. A 2014, 2 (46), 19609-19615. https://doi.org/10.1016/j.jbusres.2015.10.048.

(47) Ajdary, R.; Huan, S.; Zanjanizadeh Ezazi, N.; Xiang, W.; Grande, R.; Santos, H. A.; Rojas, O. J. Acetylated Nanocellulose for Single-Component Bioinks and Cell Proliferation on 3DPrinted Scaffolds. Biomacromolecules 2019, $20 \quad$ (7), 2770-2778. https://doi.org/10.1021/acs.biomac.9b00527.

(48) Tenhunen, T.-M.; Peresin, M. S.; Penttilä, P. A.; Pere, J.; Serimaa, R.; Tammelin, T. Significance of Xylan on the Stability and Water Interactions of Cellulosic Nanofibrils. $\begin{array}{lllll}\text { React. } & \text { Funct. } & \text { Polym. } & \text { 2014, } & \text { 85, }\end{array}$ https://doi.org/10.1016/J.REACTFUNCTPOLYM.2014.08.011.

(49) Hillman, A. R.; Jackson, A.; Martin, S. J. The Problem of Uniqueness of Fit for Viscoelastic Films on Thickness-Shear Mode Resonator Surfaces. Anal. Chem. 2001, 73 (3), 540-549. https://doi.org/10.1021/ac001065n. 
(50) Höök, F.; Kasemo, B.; Nylander, T.; Fant, C.; Sott, K.; Elwing, H. Variations in Coupled Water, Viscoelastic Properties, and Film Thickness of a Mefp-1 Protein Film during Adsorption and Cross-Linking: A Quartz Crystal Microbalance with Dissipation Monitoring, Ellipsometry, and Surface Plasmon Resonance Study. Anal. Chem. 2001, 73 (24), 5796-5804. https://doi.org/10.1021/ac0106501.

(51) Cho, N.-J.; K. Kanazawa, K.; S. Glenn, J.; W. Frank, C. Employing Two Different Quartz Crystal Microbalance Models To Study Changes in Viscoelastic Behavior upon Transformation of Lipid Vesicles to a Bilayer on a Gold Surface. Anal. Chem. 2007, 79 (18), 7027-7035. https://doi.org/10.1021/ac0709504.

(52) Home - INNPAPER https://innpaper.eu/ (accessed May 19, 2020).

(53) Shivananju, B. N.; Yamdagni, S.; Fazuldeen, R.; Kumar, A. K. S.; Nithin, S. P.; Varma, M. M.; Asokan, S. Highly Sensitive Carbon Nanotubes Coated Etched Fiber Bragg Grating Sensor for Humidity Sensing. IEEE Sens. J. 2014, 14 (8), 2615-2619. https://doi.org/10.1109/JSEN.2014.2312353.

(54) Beamson, G.; Briggs, D. High Resolution XPS of Organic Polymers: The Scienta ESCA300 Database.; Wiley: Chichester, 1992. 


\section{TABLE OF CONTENTS}
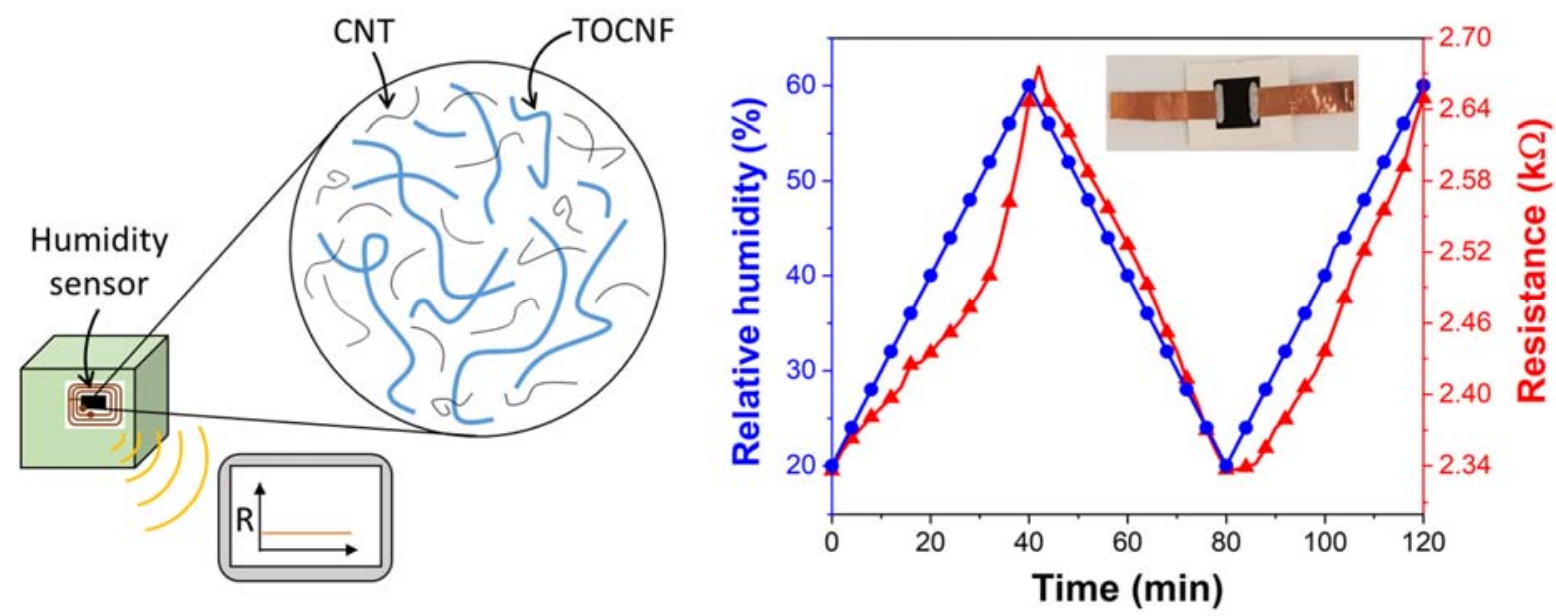